\title{
Corrigendum: "A validated model of the pro- and anti-inflammatory cytokine balancing act in articular cartilage lesion formation"
}

\author{
Xiayi Wang ${ }^{1}$, Marc J. Brouillette ${ }^{2,3}$, Bruce P. Ayati ${ }^{1,2,4 *}$ and James A. Martin ${ }^{2,3}$ \\ ${ }^{1}$ Program in Applied Mathematical and Computational Sciences, University of lowa, lowa City, IA, USA, ${ }^{2}$ Department of \\ Orthopaedics and Rehabilitation, University of lowa, lowa City, IA, USA, ${ }^{3}$ Department of Biomedical Engineering, University \\ of lowa, lowa City, IA, USA, ${ }^{4}$ Department of Mathematics, University of lowa, lowa City, IA, USA
}

Keywords: articular cartilage, structured model, lesion formation and abatement, EPO, IL-6

\section{A corrigendum on}

A validated model of the pro- and anti-inflammatory cytokine balancing act in articular cartilage lesion formation

\section{OPEN ACCESS}

Edited by:

Bernardo Innocenti, Université Libre de Bruxelles, Belgium

Reviewed by:

Thimios Mitsiadis,

University of Zurich, Switzerland

Dominique J. Dubois,

Université Libre de Bruxelles, Belgium

*Correspondence:

Bruce P. Ayati

bruce-ayati@uiowa.edu

Specialty section:

This article was submitted to Biomechanics, a section of the journal

Frontiers in Bioengineering and Biotechnology

Received: 01 May 2015 Accepted: 08 May 2015

Published: 26 May 2015

Citation:

Wang X, Brouillette MJ, Ayati BP and

Martin JA (2015) Corrigendum: "A validated model of the pro- and anti-inflammatory cytokine balancing act in articular cartilage lesion formation".

Front. Bioeng. Biotechnol. 3:73. doi: 10.3389/fbioe.2015.00073 by Wang, X., Brouillette, M. J., Ayati, B. P., and Martin, J. A. (2015). Front. Bioeng. Biotechnol. 3:25. doi: 10.3389/fbioe.2015.00025

There are a number of errors in the original manuscript (Wang et al., 2015) due to the use of incorrect versions of our material during the final manuscript preparation stage. They are

1. Figure $\mathbf{1}$ has the incorrect schematic. The figure in this corrigendum is the schematic that matches the models and simulations in the manuscript.

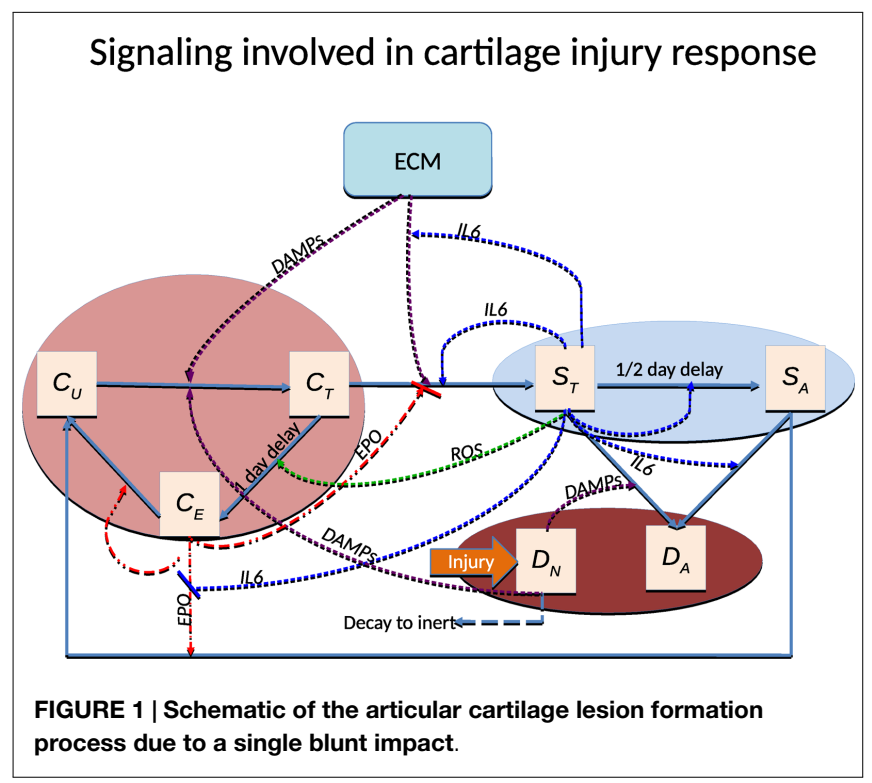


2. In equation ( $1 \mathrm{~b}), \delta_{U}$ should be $\sigma_{U}$.

3. The correct initial condition for ROS is $R(r, 0)=0$.

4. The Heaviside function is defined incorrectly in equation (2). We use the standard Heaviside function, $H(\theta)=1$ for $\theta \geq 0$, $H(\theta)=0$ for $\theta<0$.

5. In equations (5a) and (6b), the Monod functions that depend on ROS, $R$, should instead depend on DAMPs, $M$.

6. The parameter $\eta$ in equations (8a) and (9) should be $\kappa_{1}$.

7. The underbraces in equations (8a), (8b), and (9) that indicate dependence on TNF- $\alpha$ specifically should instead indicate dependence on a generic pro-inflammatory cytokine, denoted by $F$.

8. Equation (8b) does not depend on $C_{U}$. In place of $C_{U}$ in the equation there should instead be implicit multiplication by 1 .

9. In Table 2, the correct parameter value for $\delta_{F}$ is 0.1664 and the correct parameter value for $\delta_{P}$ is 0.5545 . These were obtained from the derivation in (Wang et al., 2014):

$$
\begin{aligned}
& \delta_{F}=-\frac{24}{100 \text { hour }} \ln \left(\frac{1}{2}\right)=0.1664 / \text { day }, \\
& \delta_{P}=-\frac{24}{30 \text { hour }} \ln \left(\frac{1}{2}\right)=0.5545 / \text { day }
\end{aligned}
$$

\section{References}

Brines, M., and Cerami, A. (2008). Erythropoietin-mediated tissue protection: reducing collateral damage from the primary injury response. J. Intern. Med. 264, 405-432. doi:10.1111/j.1365-2796.2008.02024.x

Ito, T., Kawahara, K., Okamoto, K., Yamada, S., Yasuda, M., Imaizumi, H., et al. (2008). Proteolytic cleavage of high mobility group box 1 protein by thrombinthrombomodulin complexes. Arterioscler. Thromb. Vasc. Biol. 28, 1825-1830. doi:10.1161/ATVBAHA.107.150631

Varshavsky, A. (1997). The N-end rule pathway of protein degradation. Genes Cells 2, 13-28. doi:10.1046/j.1365-2443.1997.1020301.x

Wang, X., Ayati, B. P., Brouillete, M. J., Graham, J. M., Ramakrishnan, P. S., and Martin, J. A. (2014). Modeling and simulation of the effects of cyclic loading on articular cartilage lesion formation. Int. J. Numer. Method Biomed. Eng. 30, 927-941. doi:10.1002/cnm.2636

Wang, X., Brouillette, M. J., Ayati, B. P., and Martin, J. A. (2015). A validated model of the pro- and anti-inflammatory cytokine balancing act in articular
Here 100 hours is the approximate half-life of TNF- $\alpha$ (Wedlock et al., 1996; Brines and Cerami, 2008) and 30 hours is the approximate half-life of DAMPs and EPO (Ito et al., 2008). To obtain the half-lives from the source literature, we used the "N-end Rule" (Varshavsky, 1997). The similarities in their half-lives are why we have that $\delta_{M}=\delta_{P}$. We note that the parameter values in Table 1 of (Wang et al., 2014) are not consistent with the correct values in the body of the text (Wang et al., 2014, pg. 931).

All the simulations in the original manuscript where conducted with these versions of the equations and parameters.

\section{Acknowledgments}

The authors thank Georgi Kapitanov for a careful reading of the manuscript and source code. Funding: XW, BA, MB, and JM were partially supported by NIAMS grant \#1 P50 AR055533. MB was supported by a Merit Review Award from the Department of Veterans Affairs.

cartilage lesion formation. Front. Bioeng. Biotechnol. 3:25. doi:10.3389/fbioe. 2015.00025

Wedlock, D. N., Aldwell, F. E., and Buddle, B. M. (1996). Molecular cloning and characterization of tumor necrosis factor alpha (TNF-alpha) from the Australian common brushtail possum, Trichosurus vulpecula. Immunol. Cell Biol. 74, 151-158. doi:10.1038/icb.1996.20

Conflict of Interest Statement: The authors declare that the research was conducted in the absence of any commercial or financial relationships that could be construed as a potential conflict of interest.

Copyright (c) 2015 Wang, Brouillette, Ayati and Martin. This is an open-access article distributed under the terms of the Creative Commons Attribution License (CC BY). The use, distribution or reproduction in other forums is permitted, provided the original author(s) or licensor are credited and that the original publication in this journal is cited, in accordance with accepted academic practice. No use, distribution or reproduction is permitted which does not comply with these terms. 